\title{
Correction to: Assessment of the Potential of Watermelon Rind Powder for the Value Addition of Noodles
}

\author{
Nayan Chakrabarty ${ }^{1}$ Mehrin Mamun Mourin ${ }^{1} \cdot$ Nawsheen Islam $^{1} \cdot$ Ahmed Redwan Haque $^{2} \cdot$ Mst. Sorifa Akter $^{1}$. \\ Md Abu Ayub Siddique ${ }^{3}$. Manobendro Sarker ${ }^{1,4,5}$
}

Published online: 30 October 2020

(C) The Korean Society for Agricultural Machinery 2020

\section{Correction to: Journal of Biosystems Engineering. https://doi.org/10.1007/s42853-020-00061-y}

Due to an unfortunate oversight, author names have been misspelt. They should be read:

Mst. Sorifa Akter and Md Abu Ayub Siddique.

Further, the affiliation of the first three authors is missing. They are affiliated with Department of Food Engineering and Technology, State University of Bangladesh, Dhaka, Bangladesh.

The online version of the original article can be found at https://doi.org/ 10.1007/s42853-020-00061-y

Manobendro Sarker

manob08@gmail.com

1 Department of Food Engineering and Technology, State University of Bangladesh, Dhaka, Bangladesh

2 Department of Food Processing and Preservation, Hajee Mohammad Danesh Science and Technology University, Dinajpur, Bangladesh

3 Department of Biosystems Machinery Engineering, Chungnam National University, Daejeon 34134, Republic of Korea

4 Biomass Energy Engineering Research Centre, School of Agriculture and Biology, Shanghai Jiao Tong University, 800 Dongchuan Road, Shanghai 200240, People's Republic of China

5 Key Laboratory of Urban Agriculture (South), Ministry of Agriculture and Rural Affairs, 800 Dongchuan Road, Shanghai 200240, People's Republic of China 